\title{
Mental Toughness in Relation with Mental Health of Sports Persons
}

\author{
Nalini Malhotra, Rupleen Kaur \\ Department of Psychology, Punjabi University, Patiala, Punjab, India
}

Email address:

drnalinimalhotra@gmail.com (N. Malhotra)

To cite this article:

Nalini Malhotra, Rupleen Kaur. Mental Toughness in Relation with Mental Health of Sports Persons. American Journal of Sports Science. Vol. 5, No. 5, 2017, pp. 31-34. doi: 10.11648/j.ajss.20170505.12

Received: October 31, 2016; Accepted: January 11, 2017; Published: October 16, 2017

\begin{abstract}
The aim of the present study was to investigate the relationship between mental toughness and mental health viz; depression, anxiety and stress among sports persons. Participants were 80 athletes $($ Male $=40$; Female $=40)$ within the age range of 17 to 21 years. Data were collected using Mental toughness questionnaire (MTQ-48) - Peter Clough, (2002) and Depression, Anxiety, Stress Scale (DASS-21) - Lovibond \& Lovibond (1995). Results revealed that there existed significant negative relationship of mental toughness with depression and anxiety but not with stress of sports persons. The implications for the present study were discussed.
\end{abstract}

Keywords: Mental Toughness, Mental Health, Sports

\section{Introduction}

Mental toughness is the voice in the back of our head that always encourage us to keep going, keep pushing, and keep trying, even when the going gets tough. "Mental toughness describes the capacity of an individual to deal effectively with stressors, pressures and challenges, and perform to the best of their ability, irrespective of the circumstances in which they find themselves." (Dr Peter Clough, 2002). The word mental toughness is a personality trait which we can define as people mindset which they adopt in all works they do. We people are living in a highly pressurized world that demands excellence and good performances every single day. Having a rock solid mindset, being nimble and malleable, and maintaining focus on goal is what differentiates the champions from the challengers.

Mental toughness is required to achieve good health, work and to achieve success in life. Mentally toughness makes people show positive, confident attitude towards the challenges and stressors of life. Mentally tough individuals show good educational performance, dealing effectively with difficult days and adversity, know how to handle situations which effect on their behavior and well-being. Clough et al. (2002) presented a 4c's model of mental toughness. According to his model Control (emotions \& life),
Commitment, Challenge, Confidence (ability \& interpersonal) are the characteristics of mental toughness. Thus, mental toughness is the prime term. Individuals go through number of obstacles in their life. Individuals with mental toughness characteristics can get advantages in every area of their life by dealing efficiently with stressful situations like in education, health, and social life.

Mental health is an important component of health. It is described as individual's level of psychological well-being, or an absence of mental disorders. It includes our emotional, psychological, and social well-being. It affects how we think, feel, and act. Our mental health can vary according to our circumstances and can change across our lifetime, in the same way as our physical health does. Mental health is defined as " a state of well-being in which every individual realize his or her own potential, can cope with normal stresses of life, can work productively and fruitfully, and is able to make a contribution to her or his community." (World Health Organization, 2014). Mental health problems are among the most common of all health conditions. Depression and stress or anxiety is the most widespread conditions. When we are free of depression, anxiety, excessive stress and worry, addictions, and other psychological problems, we are 
more able to lives to the fullest.

Mental health strengthens and supports our ability to have healthy relationships, make good choices in life, and maintain physical health and well-being, manage life hassles, discover and grow towards our goal. According to the National association of mental health (2014), there are three characteristics of mentally healthy individuals: They feel comfortable about themselves. They feel right about others. They are able to meet the demands of life. Holistic model of subjective well-being (Roy Choudhury \& Barman, 2014) has been build - up in order to assess the holistic approach of subjective well-being by examine the major components which describes the quality of life as a whole. The model consists of 2P (Psychological well-being \& Physical wellbeing) and $2 \mathrm{~S}$ (Social well-being \& Spiritual well-being) components. Thus, the main purpose of the model is to provide the comprehensive framework covering the all possible elements of subjective well-being.

Depression, Anxiety and stress are the most common issues of mental health. Depression is a most common but serious mood disorder that leads to emotional and psychological problems. Anxiety is a negative emotion which occurs when the person think that he/she has a cause to be worried about some threat that might happen. Stress is the feeling of under pressure that disturbs mental or physical well-being.

Sports can be defined as competitive physical and mental activities. A sportsperson is the person whose profession is to play sports. Team spirit, Fighting spirit, disciplined, hard work, mental toughness and positive thinking are the qualities of good sports persons. Sports persons also suffer from depression, anxiety and stress. Highly pressurized environment and number of setbacks because of any injury may lead to mental health problems. There are broad spectrum of studies show that depression, anxiety and stress are the psychological problems through which athletes suffer.

Hayashi (1998) study anxiety levels and way of coping in gymnasts in order to find out why some gymnasts continue to participates and others does not. According to the results gymnasts with higher anxiety and low ability to cope with hardship were more likely to halt participating in gymnastics competition. According to a Study conducted by Gevorki et al. (2013) found out the relation of mental toughness and mental health of professional \& amateur athletes and results revealed that mental health and mental toughness in professional athletes was significantly higher compared to that of amateur athletes. With the background of assessing mental toughness and mental health of sports persons, the following objective of the present study was formulated-

Objective - To study the mental toughness of sports persons in relation with depression, anxiety and stress.

Hypothesis - It is expected that mental toughness of sports persons would be negatively correlated with depression, anxiety and stress.

Participants- For the purpose of the present study, total sample comprising 80 sports persons (40 males and 40 females) within the age range of 17-21 years was selected. The data was collected from the sportspersons of the different plays grounds of Patiala district.

\section{Instruments}

The participants were administrated the following tests:

- Mental Toughness Questionnaire (MTQ48), (Clough et al., 2002)

- Depression, Anxiety, Stress (DASS-21) - Lovibond \& Lovibond (1995)

\section{Procedure}

In order to collect the data random sampling technique was used. Individual's having sports activities within age range of 17-21 were randomly chosen from the different play grounds. Researcher instructed the respondents, about the purpose of the study, how to fill the questionnaires. Confidentiality was assured to them.

Statistical analysis -: Keeping in mind the hypothesis of the study, correlation method was used.

\section{Results and Discussion}

The results of the present study are reported in Table 1 in which correlation of mental toughness with depression, anxiety and stress of sports persons are shown. The present study examined the relation of mental toughness with depression and results indicates that mental toughness of sports persons was significantly negatively correlated with depression $\left(-.43^{* *}\right)$. Besides the total toughness, the dimensions viz., Commitment $\left(-.33^{* *}\right)$, emotional control ($\left..37^{* *}\right)$, life control $\left(-.36^{* *}\right)$ and confidence in abilities ($\left..25^{*}\right)$ of mental toughness also found to be significantly negatively correlated with depression. White (2001) in his research work found the significant relationship between the mental toughness and mental illness (including anxiety, depression, and physical disorders), People having mental disorders have low level of mental toughness and they try to avoid any kind of pressure. According to Brand et al (2014) adolescents with high mental toughness has higher sleep efficiency. Visram (2012) research has suggested that mental toughness intervention is effective at increasing mental toughness in women's soccer and field hockey athletes. Results of the study revealed that mental toughness was related to lowering the level of athlete's burnout, depression, physical symptoms and perceived stress. 
Table 1. Showing the correlation Matrix of mental toughness, depression, anxiety and stress of sports persons.

\begin{tabular}{|c|c|c|c|c|c|c|c|c|c|c|}
\hline Variables & Challenge & $\begin{array}{l}\text { Commit } \\
\text { ment }\end{array}$ & $\begin{array}{l}\text { Emotional } \\
\text { Control } \\
\end{array}$ & $\begin{array}{l}\text { Life } \\
\text { Control } \\
\end{array}$ & $\begin{array}{l}\text { Confidence } \\
\text { in Abilities }\end{array}$ & $\begin{array}{l}\text { Interpersonal } \\
\text { Confidence }\end{array}$ & $\begin{array}{l}\text { Mental } \\
\text { toughness }\end{array}$ & Depression & Anxiety & Stress \\
\hline Challenge & 1 & & & & & & & & & \\
\hline Commitment & .12 & 1 & & & & & & & & \\
\hline Emotional Control & .06 & $.30^{* *}$ & 1 & & & & & & & \\
\hline Life Control & .18 & $.31^{* *}$ & .19 & 1 & & & & & & \\
\hline Confidence in Abilities & .12 & $.41^{* *}$ & $.31^{* *}$ & $.24^{*}$ & 1 & & & & & \\
\hline Interpersonal Confidence & $.23^{*}$ & .10 & .08 & .02 & .02 & 1 & & & & \\
\hline Depression & -.16 & $-.33^{* *}$ & $-.37^{* *}$ & $-.36^{* *}$ & $-.25^{*}$ & -.02 & $-.43^{* *}$ & 1 & & \\
\hline Anxiety & -.13 & $-.32^{* *}$ & $-.31^{* *}$ & $-.35^{* *}$ & $-.33^{* *}$ & -.14 & $-.45^{* *}$ & $.61^{* *}$ & 1 & \\
\hline Stress & .05 & -.16 & $-.30^{* *}$ & -.15 & -.08 & -.05 & -.19 & $.56^{* *}$ & $.62^{* *}$ & 1 \\
\hline
\end{tabular}

** Significance at 0.01 level. * Significance at 0.05 level.

Further, results of the present study revealed that mental toughness of sports persons was found to be negatively correlated with Anxiety (-.45**) in a significant manner. Dimensions of mental toughness viz., commitment (-.32**), emotional control $\left(-.31^{* *}\right)$, life control $\left(.-35^{* *}\right)$, confidence in abilities $\left(-.33^{* *}\right)$ also found to be significantly and negatively correlated with anxiety. Mentally tough athletes by using their mental skills strategies and positive attitude easily overcome their anxiety. According to Clough et al. (2002) mentally tough individuals tend to be sociable and outgoing; as they are able to remain calm and relaxed, they are competitive in many situations and have lower anxiety levels than others. Nicholas M. Beck (2012) found significant negative relation of mental toughness with anxiety, sadness, confusion, fatigue, and total mood disturbance, and positive significant relation with higher levels of vigor. According to Stamp et al. (2015) positive relationship exist between mental toughness and psychological well-being. Golby \& Wood (2016) in their study examined the effects of a psychological skills intervention designed to enhance the mental toughness and psychological well-being of students athlete rowers. It was found that mental toughness significantly improved in addition to perceived self-efficacy, self esteem and positive affect.

Results of the present study further revealed that mental toughness was not found to be significantly negatively correlated with stress $(-.19$, n.s). On the other hand emotional control subscale of mental toughness was found to be significantly negatively correlated with stress $\left(-.30^{* *}\right)$. Sports persons also goes through number of stressful situation, but they able to show their best, because they well know how to manage these stressful situations by using coping tabmechanism, rational thinking, pre-competition mental preparation, good attitude, behavior and smartness. Gerber et al., (2012) suggested that mental toughness reduce the relationship between high stress and depressive symptoms and is significantly negatively correlated with stress and depression. According to Gerber et al. (2013) adolescence with high mental toughness better able to manage stress. Cowden et al., (2016) found the positive relationship between Total mental toughness and resilience and negative relationship between Total mental toughness and stress. Hence, Sports persons experience lower level of stress which we can relate with their ability to control their thoughts and emotions (Golby and Sheard, 2004; Crust, 2009) that assists with the appraisal of stressors or their ability to employ more effective coping strategies (Nicholls et al., 2008; Crust and Keegan, 2010).

In conclusion, we can say that mental toughness is positively related to mental health. The present study implicates that mental toughness is a positive character of sports persons to dispel the negative effects of depression, stress and anxiety. So, that if sportspersons develop this character then their mental health would be enhanced. Athletes that are good in taking challenges, learn from their bad experiences, high on commitment for their goals and achievements, know how to control their emotions, further, show high confidence with less occurrence of depression, anxiety and stress.

\section{References}

[1] Beck, Nicholas, N., (2012). Mental toughness: An analysis of Sex, Race and Mood. Denton, Texas. UNT Digital Library.

[2] Brand, S., Gerber, M., Kalak, N., Kirov, R., Lemola, S., Clough, P, J., Puhse, U., Holsboer- Trachsler, E. (2014). Journal of adolescent Health, 54, 109-113.

[3] Clough, P. J., Earle, K., \& Sewell, D. (2002) Mental toughness: the concept and its measurement. In I. Cockerill (Ed.), Solutions in Sports Psychology (pp.32-43). London: Thomson.

[4] Clough, P.J., Earle, K., \& Sewell, D. (2002). Mental toughness: The concept and its measurement. In Kobasa SC, 1979. Stressful events, Personality, and health: An inquiry into hardiness. Journal of Personaliity and Social Psychology. 7: 413-423.

[5] Cowden RG, Meyer-Weitz A, Asante KO: Mental toughness in competitive tennis: relationships with resilience and stress. Front Psychol 2016, 7: 320. doi: 10.3389/fpsyg.2016.00320

[6] Crust L., Keegan R. (2010). Mental toughness and attitude to risk-taking. Pers. Individ Differ: 49 164-168. 10. 1016/j.paid.2010.03.026

[7] Crust. L. (2009). The relationship between mental toughness and affect intensity. Pers. Individ. Differ. 47, 959-963. doi: 10.1016/j.paod.2009.07.023 
[8] Gerber, M., Brand, S., Feldmeth, A.K., Lang, K., Elliot, K., Holsboer-Trachsler, E., Puhse, U. (2013). Personality and Individual differences, 54, 808-814.

[9] Gerber, M., Kalak, N., Lemola, S., Clough, P.J., Perry, L.L. Puhse, U., Elliot, C.E., Trachsler E. H., Brand, S., (2012). Are Adolescents with High Mental Toughness Levels More Resilient Against Stress? Stress and Health, 29, 164-171.

[10] Gevorki, H., Gevorki, E., \& Samadi, H. (2013). Comparing of mental toughness \& mental health of professional and amateur athletics. International Journal of Basic Sciences \& Applied Research, 2 (6), 583- 588.

[11] Golby, J., \& Wood, P. (2016). The Effects of Psychological Skills Training On Mental Toughness and Psychological WellBeing of Students Athletes. Psychology, 2016, 7, 901-913.

[12] Golby, J., and Sheard, M. (2004). Mental toughness and hardiness at different levels of rugby league. Pers. Individ. Differ. 37, 933-942. doi : 10.1016/j.paid.2003.10.015

[13] Hayashi, S. W. (1998). Understanding youth sport participation through perceived behaviors, social support, anxiety and coping. Un-published control doctoral dissertation, Michigan state university, Lansing, M1. Microform publications, University of Oregon.
[14] Nicholls A., Polman R., Levy A., Backhouse S. (2008). Mental toughness, optimism, pessimism, and coping among athletes. Pers. Individ. Differ. 44 1182- 1192. 10.1016/j.paid.2007.11.011

[15] Roy Choudhury, Satabdi \& Barman, Dr. Arup, "Holistic Model of Subjective Well-being- A Proposed Model and Exploration of Contents", ZENITH International Journal of Multidisciplinary Research, ISSN 2231-5780 Vol. 4(3). MARCH (2014), Online available at zenithresearch.org.in.

[16] Stamp, E.; Crust, L.; Swann, C.; Perry, J.; Clough, P.; Marchant, D (2015). Relationship between mental toughness and psychological wellbeing in undergraduate students. Personality and Individual Differences 75(2015) 170-174.

[17] Visram, A. (2012). Impact of mental toughness training on psychological and physical predictors of illness and injury (Master's Thesis). Retrieved fromhttp://scholarworks.umass.edu/cgi/viewcontent.cgi?articl $\mathrm{e}=1935 \&$ context $=$ theses.

[18] White J, 2001. Mental health concepts and skill online. Salem-Keizer public Schools. 